\title{
Rationale for the design of an oncology trial using a generic targeted therapy multi-drug regimen for NSCLC patients without treatment options (Review)
}

\author{
STEFAN LANGHAMMER \\ Life Science Consulting, Schloss Pesch, D-40668 Meerbusch, Germany
}

Received May 29, 2013; Accepted July 5, 2013

DOI: $10.3892 /$ or.2013.2631

\begin{abstract}
Despite more than 70 years of research concerning medication for cancer treatment, the disease still remains one of the leading causes of mortality worldwide. Many cancer types lead to death within a period of months to years. The original class of chemotherapeutics is not selective for tumor cells and often has limited efficacy, while treated patients suffer from adverse side-effects. To date, the concept of tumor-specific targeted therapy drugs has not fulfilled its expectation to provide a key for a cure. Today, many oncology trials are designed using a combination of chemotherapeutics with targeted therapy drugs. However, these approaches have limited outcomes in most cancer indications. This perspective review provides a rationale to combine targeted therapy drugs for cancer treatment based on observations of evolutionary principles of tumor development and HIV infections. In both diseases, the mechanisms of immune evasion and drug resistance can be compared to some extent. However, only for HIV is a breakthrough treatment available, which is the highly active antiretroviral therapy (HAART). The principles of HAART and recent findings from cancer research were employed to construct a hypothetical model for cancer treatment with a multi-drug regimen of targeted therapy drugs. As an example of this hypothesis, it is proposed to combine already marketed targeted therapy drugs against VEGFRs, EGFR, CXCR4 and COX2 in an oncology trial for non-small cell lung cancer patients without further treatment options.
\end{abstract}

\section{Contents}

1. Overview of the mechanisms of anticancer drugs

2. Comparison of the biological principles of tumor development and HIV infection

Correspondence to: Dr Stefan Langhammer, Life Science Consulting, Schloss Pesch, Ossum 14, D-40668 Meerbusch, Germany

E-mail: langhammer@1s-consultant.net

Key words: targeted therapy drugs, drug resistance, multi-drug regimen, HIV, highly active antiretroviral therapy
3. Breakthrough in HIV treatment through the prevention of viral resistance using a multi-drug regimen of targeted therapy drugs

4. Implications for the design of a generic oncology trial with a multi-drug regimen using targeted therapy drugs for NSCLC patients not indicated for treatment

\section{Overview of the mechanisms of anticancer drugs}

Drugs for cancer treatment can be classified into the categories of chemotherapeutic drugs and targeted therapy drugs. Examples of chemotherapeutic drugs include alkylating or alkylating-like agents such as capecitabine, mitotic inhibitors such as paclitaxel and topoisomerase inhibitors such as irinotecan. All of these drugs act as cytotoxic or cytostatic agents by killing rapidly dividing cells.

Targeted therapy agents include endocrine therapy drugs such as tamoxifen, antigrowth factor drugs such as the monoclonal antibody trastuzumab against Her2 or the receptor tyrosine kinase inhibitor (RTKI), gefitinib against the epidermal growth factor receptor (EGFR) and anti-angiogenesis drugs such as the monoclonal antibody bevacizumab against vascular endothelial growth factor (VEGF) or the RTKI sunitinib against VEGF receptors (VEGFRs) (1). All of these drugs act by specifically blocking signal transduction pathways involved in tumor development.

Historically, chemotherapeutic drugs were the first effective agents used against malignant diseases. In the 1940s it was discovered that a derivate of a chemical warfare agent, nitrogen mustard, was effective for treating lymphoma when applied to patients intravenously $(2,3)$. Cytotoxic chemotherapies are based on the classical 'principles of chemotherapy' as defined by the observance that tumors exhibit a sigmoid-shaped Gompertzian growth curve and thus cytoxic drugs are most effective in killing tumor cells within the logarithmic growth phase (4). For many cancer indications, cytotoxic chemotherapeutics are still the recommended first-line therapy. These agents include the platinum-based drugs cisplatin or carboplatin for non-small cell lung cancer (NSCLC) (5) or capecitabine in combination with oxaliplatin for colorectal cancer $(6,7)$. This class of drugs does not differentiate between cancerous and normal cells and thus induces systemic toxicity and adverse reactions $(8,9)$. The current survival rates of cancer patients 
mostly treated with cytotoxic chemotherapeutics and/or undergoing surgery and/or radiation therapy depends very much on the site of the primary tumor. Female breast in situ, uterine corpus and melanoma have 10 -year relative survival rates of up to $100 \%$ (female breast in situ). In contrast the 5-year survival rate of patients with NSCLC and liver cancer is $\sim 15 \%$ and in pancreatic cancer $\sim 5 \%$ since cytotoxic chemotherapeutics are unable to cure metastatic disease even after successful surgical tumor resection $(10,11)$.

In contrast to cytotoxic chemotherapeutics, the concept of targeted therapy is aimed to specifically target a biological pathway that is critical for tumor development or tumor maintenance and that causes regression or destruction of the malignant process when it is inhibited (12). Endocrine therapy drugs were developed for inhibition or modulation of hormone receptors for hormone-sensitive tumors. The estrogen receptor modulator (SERM) tamoxifen was the first targeted therapy drug for anticancer treatment selectively inhibiting estrogen binding to its receptor (13). When administered as an adjuvant therapy for primary treatment of estrogen receptor (ER)-sensitive breast cancer, tamoxifen was shown to reduce relapse and mortality rates (14), and to decrease recurrence rates in ER-positive breast cancer patients by $50 \% 15$ years after diagnosis (13).

Another example of targeted therapy drugs are inhibitors against the EGFR. EGFR is a well characterized example of a growth factor receptor which plays a central role in tumor development when becoming overexpressed and/or mutated. Overexpression and mutation of EGFR leads to proliferation, invasion of surrounding tissues, angiogenesis and distant metastasis (15). Activation of EGFR was also shown to influence resistance to cytotoxic chemotherapeutic agents. Intracellular signaling leading to all of these EGFR-mediated processes include the MAP kinase pathway, PI3K and Akt signaling. Several targeted therapy drugs have been approved by the FDA and EMEA for blocking the EGFR pathway either by binding to its ligand EGF (mAb panitumumab) or by inhibiting its tyrosine kinase activity (mAb cetuximab and RTKIs gefitinib and erlotinib) (16,17). Gefitinib (Iressa) for example is an orally available small-molecule RTKI (18) approved for the first-line therapy of NSCLC patients with activating mutations of the EGFR tyrosine kinase domain (19). In a subgroup of the INTEREST trial including patients with activating EGFR mutations, gefitinib was shown to improve the progression-free survival (PFS) but not the overall survival (OS) when compared to docetaxel. The median survival of patients under gefitinib treatment was 14.2 months compared to 7.6 months in the overall population (20).

Since the discovery of the impact of angiogenesis on tumor biology by Folkman (21) several angiogenesis targets have been confirmed, and small-molecule RTKIs and monoclonal antibodies have been approved as targeted therapies for the treatment of different types of malignancies $(22,23)$. One of the most prominent anti-angiogenic targets is the signal transduction by the VEGF via its receptors VEGR1-3. The monoclonal antibody bevacizumab (Avastin) binds to VEGF and was the first approved anti-angiogenic therapy. Today bevacizumab is used as a first-line therapy for colorectal cancer (CRC) and metastatic renal cell carcinoma (mRCC) (24). Several small molecule RTKIs that target VEGFRs have been approved for anticancer treatment. Among them are sunitinib (Sutent) for RCC and GIST, sorafenib (Nexavar) for RCC and inoperable HCC and vandetanib (Caprelsa) for late stage medullary thyroid cancer (25). However, the development of breakthrough targeted therapies based on anti-angiogenic and anti-growth cancer treatment has been unsuccessful until recently $(26,27)$. Prolongation of survival by targeted therapies alone or in combination with cytotoxic chemotherapeutics often can only be achieved for several months to several years. Treatment of mRCC with sunitinib improved the OS by more than 2 years compared to treatment with interferon- $\alpha$ (28). Bevacizumab in combination with chemotherapy was found to prolong the life of patients with metastatic CRC only by 4 to 5 months (29). Drawbacks associated with the application of this class of drugs include resistance to anti-angiogenic therapies mediated by the tumor microenvironment and stromal cells (30) and induction of tumor invasiveness (31). The most recent example of this failure is the revoke of FDA approval for the monoclonal anti-VEGF antibody bevacizumab for treatment of Her2-negative metastatic breast carcinoma at the end of 2011 due to its unfavorable risk-benefit profile. It could not be shown that bevacizumab significantly delays tumor growth or prolong the lives of women with breast cancer (32). Today, the design of clinical trials in oncology focuses on the combination of cytotoxic chemotherapeutics with targeted therapies. Biomarkers are used to stratify patients in order to predict the responsiveness for drug dose selection or to monitor therapy effectiveness of certain targeted therapy drugs (33).

\section{Comparing the biological principles of tumor develop- ment and HIV infection}

In many diseases of different origins, common underlying biological mechanisms play central roles. For example, the dysregulation of EGFR signal transduction is an important hallmark of certain malignancies as described above $(17,34)$ and at the same time plays a critical role in poxvirus spreading (35). Inhibitors against EGFR developed for anticancer treatment are effective against poxvirus infections (36). The observation and the analysis of common mechanisms in different types of diseases provide the opportunity to draw conclusions from the treatment of one disease to another. In a holistic model, the mechanisms of an HIV-1 infection and tumor development are comparable to a certain extent. These entirely different diseases have common features that follow the principles of the Darwinian evolutionary system. HIV-1 comprises a viral genome of $\sim 9,700$ bases of single-stranded RNA (37) and replicates within an estimated average total of $10.3 \times 10^{9}$ virions/day (38). Thus, the disease driver of an HIV infection is primarily the replication rate (39) in combination with a high mutation rate introduced by the lack of proof-reading mechanism of the transcriptase enzyme (40) and secondarily the genetic variability (41). In tumor cells, the conditions are exactly opposite. The genome of a malignant human cell consists of $\sim 3.2 \times 10^{9}$ base pairs, while its replication takes $\sim 1-2$ days $(42,43)$. Thus, in tumors, the genetic heterogeneity instead of the replication rate is the primary evolutionary driver (44-47). Most importantly, in both diseases, in malignancies and in HIV infections, the immune system is unable to control the disease due to the evolutionary drivers that steer 
the processes of evasion from immunological responses. In HIV infections and in tumor development, these mechanisms include the generation of escape mutants and the suppression of the immune system $(43,48-54)$. Additionally in tumor development the regulation of rescue pathways plays a critical role to evade immunological responses $(55,56)$.

\section{Breakthrough in HIV treatment through the prevention of viral resistance using a multi-drug regimen of targeted therapy drugs}

Despite the anticipated common underlying biological mechanisms of HIV infections and tumor development, the development of an effective therapy concept against HIV was a great success while there is still no groundbreaking treatment for many types of cancer. At the beginning of the HIV epidemic, patients were treated with monotherapy of the nucleoside analogue reverse transcriptase inhibitor (NRTI) zidovudine developed in 1964. NRTIs selectively inhibit HIV reverse transcriptase and thereby specifically block transcription of viral DNA from viral RNA. Even though this treatment exhibited some effect, the rates of progression-free survival were still low. In a hemophilic cohort of 111 patients treated solely with zidovudine and followed up for 11 years, the progression rates to AIDS, symptoms and death were as high as $85 \%$ (57). In 1996, only 16 years after the identification of HIV as the cause of AIDS, the breakthrough in HIV therapy was achieved when targeted therapy drugs were applied in a combinational protocol introducing the highly active antiretroviral therapy (HAART) (58). One year later the clinical superiority of a three-drug regimen over a two-drug regimen by using the selective protease inhibitor indinavir together with the NRTIs zidovudine and lamivudine was demonstrated (59). Today, HAART consists of at least three drugs, including either a protease inhibitor or a non-NRTI (NNRTI) and two NRTIs. All three different drugs used in HAART are selective targeted therapy compounds against critical steps in the HIV-1 replication cycle. The drug class of HIV-1 protease inhibitors is among the first successful examples of highly selective targeted therapy drugs (60). A prospective cohort study evaluated the long-term effectiveness of HAART and showed a reduction in the progression to AIDS or death by $86 \%(61)$.

The successful treatment of HIV by HAART shows that it is possible to control a disease that follows an evolutionary concept similar to cancer. In both diseases, primary evolutionary factors, a high replication rate in HIV and a large genomic variability in cancer, define the route of evasion from immunological responses. HAART is successful because it is based on two key principles of treatment: i) high selectivity of drugs against disease-specific targets, thus preventing severe toxicities, adverse reactions and damage of immune system components; and ii) effective combination of disease-specific targets, thus preventing evolutionarily driven generation of escape mutants and drug resistances. Transferring these principles to cancer treatment would mean to address tumor targets as selective as possible reducing side-effects and to identify a multi-drug regimen of targeted therapy drugs for each type of malignancy preventing tumor cell rescue and drug resistance. However, at present most of the current anticancer drug therapies consist of chemotherapeutics that do not follow the principle of drug selectivity (5-7). These therapies lead to dose-dependent side-effects and adverse reactions but mostly have a modest to moderate effect on the malignant disease by prolonging survival times only by a few months to years at maximum (10). Most of these treatments have toxic effects on the hematological system and lead to opportunistic infections that have to be controlled in parallel to the chemotherapeutic treatment $(8,62,63)$.

\section{Implications for the design of a generic oncology trial with a multi-drug regimen using targeted therapy drugs for NSCLC patients not indicated for treatment}

Lung cancer is the leading cause of cancer-related mortality worldwide. Histopathological grading identifies $\sim 85 \%$ of lung cancers as NSCLCs and 15-20\% as small-cell lung cancers (SCLCs). NSCLCs can be subdivided into squamous cell carcinoma and adenocarcinoma, accounting for 34 and $55 \%$ respectively, and into other subtypes such as large cell carcinoma (64). For NSCLC cases up to grade IIIA, the standard of care is surgical resection of the primary tumor which can be supported by adjuvant chemotherapy and/or radiotherapy. However, most often NSCLC is diagnosed at advanced stages beyond stage IIIB. These tumors are treated with first-line neoadjuvant chemotherapies followed by tumor resection or alternatively combined with radiotherapy. First-line chemotherapies against NSCLC consist of platinum-based drugs (carboplatin or cisplatin) combined with third generation cytotoxic drugs such as docetaxel, paclitaxel, irinotecan, gemcitabin, vinorelbin and pemetrexed (5). Several targeted therapy drugs have been approved for the treatment of NSCLC. These include gefitinib, approved for first line therapy of NSCLC with activating mutations of the EGFR tyrosine kinase domain (19) and bevacizumab approved for treatment of non-squamous NSCLC in combination with platinium-based therapy (65). Another targeted therapy drug is crizitonib which inhibits the EML4-ALK fusion protein, an oncogenic driver in a small percentage of NSCLC patients (66). Second-line therapies include docetaxel, erlotinib, gefitinib, pemetrexed and platinum-based therapy (5). The 5-year survival rate for NSCLC patients is only $\sim 15 \%$ (10) and thus the medical need for the development of effective treatment concepts for NSCLC patients is one of the greatest challenges for health care systems worldwide.

For the design of a clinical trial for NSCLC patients without further treatment options based on the concept of selectivity and adequate target combination as discussed above, four signaling pathways appear to be suitable targets against which drugs are already marketed in different indications:

VEGFR2-VEGF. VEGF signaling is a well characterized target complex with proven importance for tumor angiogenesis and tumor development, including NSCLC (27). Among the VEGF receptors VEGFR2 facilitates tumor growth by inducing angiogenesis in tumor endothelial cells (67). Evidence suggests that VEGFR2 signaling also influences the motility of tumor cells, such as in pancreatic cancer cells (68). Signal transduction by VEGFR2 is mediated through the Ras/Raf kinase pathway connected to MAP kinase signaling and the PI3K/Akt pathway 


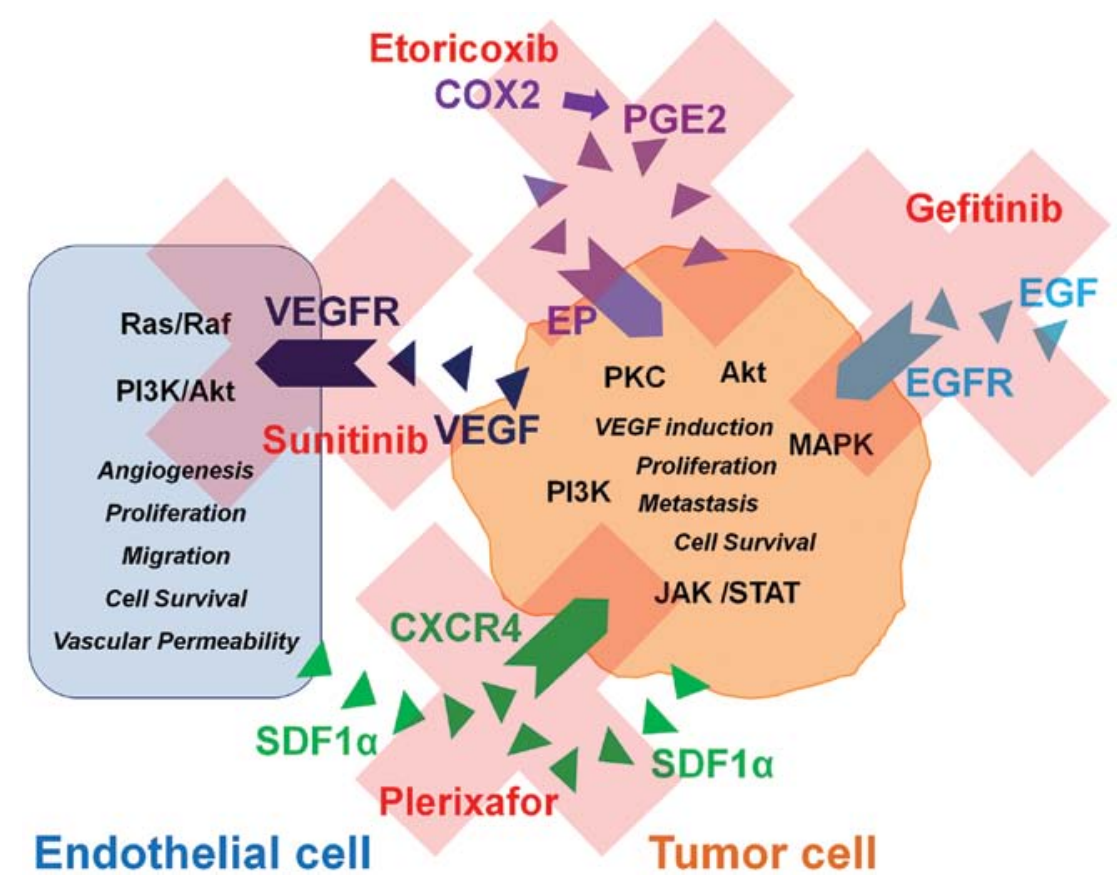

Figure 1. Hypothesis of overcoming the resistance to cancer treatment by the inhibition of different signaling pathways involved in non-small cell lung cancer (NSCLC) tumor growth by a multi-drug regimen of targeted therapy drugs. Intracellular signaling pathways activated by VEGFR, EGFR, CXCR4 and E-prostanoid receptors (EP) in tumor cells and in endothelial cells found to be involved in NSCLC tumor growth and maintenance are shown. Recent observations indicate the existence of crosstalk mechanisms between several of these pathways leading to resistance against single-agent targeted therapies alone or in combination with chemotherapeutics. Multiple inhibition of intracellular connected pathways may overcome the tumor insensitivity for targeted therapies. Targeted therapy drugs such as sunitinib, gefitinib, etoricoxib and plerixafor are clinically evaluated and FDA approved. PGE2, prostaglandin E2; VEGFR, vascular endothelial growth factor receptor; EGFR, epidermal growth factor receptor; COX2, cyclooxygenase 2.

inducing angiogenesis by mediating cell proliferation and cell-survival of tumor endothelial cells (69). For blocking the VEGF/VEGFR2 signaling pathway, several targeted therapy drugs are available. These include the small-molecule RTKI sunitinib and the monoclonal antibody bevacizumab. Sunitinib is a multi-targeted tyrosine kinase inhibitor against VEGF receptors that also inhibits the activity of other tyrosine kinases shown to be involved in tumor growth (70). Bevacizumab is directed against VEGF and blocks binding of this ligand to VEGF receptors (71). Tumors that have been treated with selective VEGFR2 inhibitors develop hypoxic microenvironments by a compromised blood supply. It was shown that this effect is countered by upregulation of growth factors which have the capacity to replace VEGF and stimulate new blood vessel growth such as EGF and SDF1 $\alpha$ as well as their receptors (30).

CXCR4-SDFI $\alpha$. The observation that treatment resistance to the blockage of VEGFR2 is mediated by EGF and SDF1 $\alpha$ and their receptors qualifies these pathways as further potential targets for a multi-drug-regimen targeted therapy for NSCLC treatment. SDF1 $\alpha$ and its receptors CXCR4 and CXCR7 were previously shown to be involved in tumor development and tumor metastasis (72-74). SDF1 $\alpha$ signal transduction through CXCR4 is a well described pathway that leads to activation of JAK/Stat, MAPK/ERK and PI3K with phosphorylation of Akt $(75,76)$. CXCR4 activation plays a role in tumor metastasis, induction of tumor growth and rescue of tumor cells from apoptosis $(77,78)$. CXCR7 was recently identified as a receptor that affects tumor cell survival (79). SDF1 $\alpha$ was shown to mediate the homing of hematologic stem cells to the bone marrow via
CXCR4 signaling (80). High expression of CXCR4 correlates with insensitivity against treatment with sunitinib in mRCC and thus represents a possible mediator of therapy resistance in tumors (81). In addition, evidence indicates that SDF1 $\alpha / C X C R 4$ signaling induces EGFR activation in human trophoblast cells (82). Interestingly, a selective targeted therapy drug, plerixafor, against CXCR4 has been approved by the FDA for mobilization of hematopoietic stem cells from the bone marrow for collection from peripheral blood for autologous stem-cell transplantation in patients with non-Hodgkin's lymphoma (NHL) or multiple myeloma (MM) (83). Plerixafor shows an excellent safety profile even when administered in combination with cytotoxic chemotherapy in cancer patients (84). Most importantly, in an experimental setting, plerixafor was shown to be effective for the treatment of metastatic lung cancer, including NSCLC (72) and in inhibition of invasiveness of human CRC cells (85).

EGFR-EGF. A further candidate of a targeted therapy multi-drug regimen is the EGFR oncogene pathway. Evidence for the increased expression of EGF in tumors treated with VEGFR inhibitors has been provided (30). As described above, inhibitors against EGFR signaling have already been approved for the treatment of EGFR-activated NSCLCs (19). Furthermore EGFR signal transduction steers similar intracellular signaling cascades such as the SDF1 $\alpha /$ CXCR4 axis, PI3K/Akt and MAPK (ERK1/2) (17) and thus may also be involved in drug resistance. In addition, EGFR was found to increase the expression of angiogenic factors such as the enzyme cyclooxygenease 2 (COX2) (86). 
COX2-E-prostanoid receptors (EP). The COX2 metabolic pathway results in the production of prostaglandin E2 (PGE2) which activates G-protein coupled EP. COX2 is increased in cancer and other pathological conditions and is suspected to participate in carcinogenesis and in tumor angiogenesis. It was shown that the COX2 pathway indirectly induces the upregulation of VEGF via the PKC pathway in NSCLC and in human lung fibroblasts $(87,88)$. COX2 was reported to increase the expression of SDF1 $\alpha$ and CXCR4 via PGE2 in myeloid-derived suppressor cells in ascites from ovarian cancer patients (89) and that it contributes to cell survival of human bladder cancer cells (90). In an experimental setting, the selective inhibition of COX2 reduced the growth of colon carcinoma cells in vivo (91). In malignant gliomas, COX2 inhibitors are currently been discussed for use in cancer treatment (92). Several selective targeted therapy drugs against COX2 [such as celecoxib (Celebrex) and etoricoxib (Arcoxia)] have been approved for the treatment of arthritis, osteoarthritis, dysmenorrhea and acute pain. The possible involvement in tumor development and the connection between COX2 signaling and the induction of VEGF, SDF1 $\alpha$ and CXCR4 qualifies this enzyme as a potential candidate for a multi-drug regimen therapy for cancer treatment.

The combined use of inhibitors against VEGFR signaling, such as sunitinib or bevacizumab combined with the CXCR4 inhibitor plerixafor and an inhibitor of EGFR signaling such as gefitinib and the COX2 inhibitor etoricoxib would block multiple signaling pathways in NSCLC. These pathways would be blocked at the receptor level while inhibiting multiple intracellular connected downstream pathways involved in tumor development and treatment resistance (Ras/Raf, PI3K/Akt, Jak/Stat, MAPK, PKC) (Fig. 1). Thus, the simultaneous inhibition of intracellular connected pathways in NSCLC tumors may overcome resistance mechanisms to targeted therapy drugs commonly noted in monotherapies or in a combination of targeted therapies with chemotherapeutics. All of the mentioned drugs are approved for different indications, and therefore their clinical profiles such as pharmacokinetics, pharmacodynamics and toxicities are well known. They are readily available as study drugs for usage in a clinical trial.

In order to identify NSCLC patient subgroups that may respond to this therapeutic concept, inclusion criteria should require the proof of expression of the respective targets. Bronchoscopy is a standard diagnostic procedure in NSCLC that allows biopsy of tumor tissue. The collected tumor specimens can easily be used for mRNA expression analysis of the respective targets by specific RT-real time PCR or by a customized gene expression array.

Similar to treatment of HIV by HAART, the herein proposed combination of targeted therapy drugs for antitumor treatment would fulfill the requirement of i) being highly selective and ii) inhibiting multiple targets involved in disease mechanism simultaneously. This may offer the chance for NSCLC patients beyond treatment to achieve an antitumor effect.

\section{References}

1. Wang B, Rosano JM, Cheheltani R, Achary MP and Kiani MF Towards a targeted multi-drug delivery approach to improve therapeutic efficacy in breast cancer. Expert Opin Drug Deliv 7: $1159-1173,2010$
2. Gilman A: The initial clinical trial of nitrogen mustard. Am J Surg 105: 574-578, 1963.

3. Papac RJ: Origins of cancer therapy. Yale J Biol Med 74: 391-398, 2001.

4. Dorr RT and Von Hoff DD: The Cancer Chemotherapy Handbook. 2nd edition. Appleton \& Lange, East Norwalk, CT, p5, 1994.

5. Azzoli CG, Temin S and Giaccone G: 2011 focused update of 2009 American Society of Clinical Oncology clinical practice guideline update on chemotherapy for stage IV non-small-cell lung cancer. J Oncol Pract 8: 63-66, 2012.

6. Porschen R, Arkenau HT, Kubicka S, Greil R, Seufferlein T, Freier W, Kretzschmar A, Graeven U, Grothey A, Hinke A, Schmiegel W and Schmoll HJ: Phase III study of capecitabine plus oxaliplatin compared with fluorouracil and leucovorin plus oxaliplatin in metastatic colorectal cancer: a final report of the AIO Colorectal Study Group. J Clin Oncol 25: 4217-4223, 2007.

7. Madi A, Fisher D, Wilson RH, Adams RA, Meade AM, Kenny SL, Nichols LL, Seymour MT, Wasan H, Kaplan R and Maughan TS: Oxaliplatin/capecitabine vs oxaliplatin/infusional 5-FU in advanced colorectal cancer: the MRC COIN trial. Br J Cancer 107: 1037-1043, 2012.

8. Hassett MJ, O'Malley AJ, Pakes JR, Newhouse JP and Earle CC: Frequency and cost of chemotherapy-related serious adverse effects in a population sample of women with breast cancer. J Natl Cancer Inst 98: 1108-1117, 2006.

9. Altena R, Perik PJ, van Veldhuisen DJ, de Vries EG and Gietema JA: Cardiovascular toxicity caused by cancer treatment: strategies for early detection. Lancet Oncol 10: 391-399, 2009.

10. Howlader N, Noone A, Krapcho M, Neyman N, Aminou R, Waldron W, Altekruse SF, Kosary CL, Ruhl J, Tatalovich Z, Cho H, Mariotto A, Eisner MP, Lewis DR, Chen HS, Feuer EJ and Cronin KA: SEER Cancer Statistics Review, 1975-2009. Vintage 2009 Populations. National Cancer Institute, Bethesda, MD, 2012.

11. Ardizzoni A, Boni L, Tiseo M, Fossella FV, Schiller JH, Paesmans M, Radosavljevic D, Paccagnella A, Zatloukal P, Mazzanti P, Bisset D and Rosell R; CISCA (CISplatin versus CArboplatin) Meta-analysis Group: Cisplatin- versus carboplatin-based chemotherapy in first-line treatment of advanced non-small-cell lung cancer: an individual patient data meta-analysis. J Natl Cancer Inst 99: 847-857, 2007.

12. Ross JS, Schenkein DP, Pietrusko R, Rolfe M, Linette GP, Stec J, Stagliano NE, Ginsburg GS, Symmans WF, Pusztai L and Hortobagyi GN: Targeted therapies for cancer 2004. Am J Clin Pathol 122: 598-609, 2004.

13. Swaby RF, Sharma CG and Jordan VC: SERMs for the treatment and prevention of breast cancer. Rev Endocr Metab Disord 8: 229-239, 2007.

14. Early Breast Cancer Trialists' Collaborative Group (EBCTCG): Effects of chemotherapy and hormonal therapy for early breast cancer on recurrence and 15-year survival: an overview of the randomised trials. Lancet 365: 1687-1717, 2005.

15. Grandis JR and Sok JC: Signaling through the epidermal growth factor receptor during the development of malignancy. Pharmacol Ther 102: 37-46, 2004.

16. Dutta PR and Maity A: Cellular responses to EGFR inhibitors and their relevance to cancer therapy. Cancer Lett 254: 165-177, 2007.

17. Okamoto I: Epidermal growth factor receptor in relation to tumor development: EGFR-targeted anticancer therapy. FEBS J 277: 309-315, 2010.

18. Harandi A, Zaidi AS, Stocker AM and Laber DA: Clinical efficacy and toxicity of anti-EGFR therapy in common cancers. J Oncol 2009: 567486, 2009.

19. Sequist LV: First-generation epidermal growth factor receptor tyrosine kinase inhibitors in EGFR mutation: positive non-small cell lung cancer patients. J Thorac Oncol 3: 143-145, 2008.

20. Douillard JY, Shepherd FA, Hirsh V, et al: Molecular predictors of outcome with gefitinib and docetaxel in previously treated non-small-cell lung cancer: data from the randomized phase III INTEREST trial. J Clin Oncol 28: 744-752, 2010.

21. Folkman J: Tumor angiogenesis: therapeutic implications. New Engl J Med 285: 1182-1186, 1971.

22. Folkman J: Angiogenesis: an organizing principle for drug discovery? Nat Rev Drug Discov 6: 273-286, 2007.

23. National Cancer Institute: Angiogenesis inhibitors. FactSheet. http://www.cancer.gov/cancertopics/factsheet/Therapy/angiogenesis-inhibitors. Revised October 7, 2011.

24. Heath VL and Bicknell R: Anticancer strategies involving the vasculature. Nat Rev Clin Oncol 6: 395-404, 2009. 
25. Ivy SP, Wick JY and Kaufman BM: An overview of small-molecule inhibitors of VEGFR signaling. Nat Rev Clin Oncol 6: 569-579, 2009

26. Jayson GC, Hicklin DJ and Ellis LM: Antiangiogenic therapy evolving view based on clinical trial results. Nat Rev Clin Oncol 9: 297-303, 2012.

27. Ebos JM and Kerbel RS: Antiangiogenic therapy: impact on invasion, disease progression, and metastasis. Nat Rev Clin Oncol 8: 210-221, 2011.

28. Oudard S, Beuselinck B, Decoene J and Albers P: Sunitinib for the treatment of metastatic renal cell carcinoma. Cancer Treat Rev 37: 178-184, 2011.

29. Hurwitz H, Fehrenbacher L, Novotny W, Cartwright T, Hainsworth J, Heim W, Berlin J, Baron A, et al: Bevacizumab plus irinotecan, fluorouracil, and leucovorin for metastatic colorectal cancer. N Engl J Med 350: 2335-2342, 2004.

30. Bergers G and Hanahan D: Modes of resistance to anti-angiogenic therapy. Nat Rev Cancer 8: 592-603, 2008.

31. Shojaei F: Anti-angiogenesis therapy in cancer: current challenges and future perspectives. Cancer Lett 320: 130-137, 2012.

32. Tanne JH: FDA cancels approval for bevacizumab in advanced breast cancer. BMJ 343: d7684, 2011.

33. Goulart BH, Clark JW, Pien HH, Roberts TG, Finkelstein SN and Chabner BA: Trends in the use and role of biomarkers in phase I oncology trials. Clin Cancer Res 13: 6719-6726, 2007.

34. Yarden Y: The EGFR family and its ligands in human cancer. Signaling mechanisms and therapeutic opportunities. Eur J Cancer 37: S3-S8, 2001.

35. Buller RM, Chakrabarti S, Moss B and Fredrickson T: Cell proliferative response to vaccinia virus is mediated by VGF. Virology 164: 182-192, 1988.

36. Langhammer S, Koban R, Yue $\mathrm{C}$ and Ellerbrok H: Inhibition of poxvirus spreading by the anti-tumor drug Gefitinib (Iressa). Antiviral Res 89: 64-70, 2011.

37. Ratner L, Fisher A, Jagodzinski LL, Mitsuya H, Liou RS, Gallo RC and Wong-Staal F: Complete nucleotide sequences of functional clones of the AIDS virus. AIDS Res Hum Retroviruses 3: 57-69, 1987.

38. Perelson AS, Neumann AU, Markowitz M, Leonard JM and Ho DD: HIV-1 dynamics in vivo: virion clearance rate, infected cell life-span, and viral generation time. Science 271: 1582-1586, 1996.

39. Campbell TB, Schneider K, Wrin T, Petropoulos CJ and Connick E: Relationship between in vitro human immunodeficiency virus type 1 replication rate and virus load in plasma. J Virol 77: 12105-12112, 2003.

40. Ho DD, Neumann AU, Perelson AS, Chen W, Leonard JM and Markowitz M: Rapid turnover of plasma virions and CD4 lymphocytes in HIV-1 infection. Nature 373: 123-126, 1995.

41. Hemelaar J: The origin and diversity of the HIV-1 pandemic. Trends Mol Med 18: 182-192, 2012.

42. Klein CA: Parallel progression of primary tumors and metastases. Nat Rev Cancer 9: 302-312, 2009.

43. Greaves M and Maley CC: Clonal evolution in cancer. Nature 481: 306-313, 2012.

44. Merlo LM, Pepper JW, Reid BJ and Maley CC: Cancer as an evolutionary and ecological process. Nat Rev Cancer 6: 924-935, 2006.

45. Maley CC, Galipeau PC, Finley JC, Wongsurawat VJ, Li X, Sanchez CA, Paulson TG, Blount PL, Risques RA, Rabinovitch PS and Reid BJ: Genetic clonal diversity predicts progression to esophageal adenocarcinoma. Nat Genet 38: 468-473, 2006.

46. Pepper J, Findlay CS, Kassen R, Spencer S and Maley CC: Cancer research meets evolutionary biology. Evol Appl 2: 62-70, 2009.

47. González-García I, Solé RV and Costa J: Metapopulation dynamics and spatial heterogeneity in cancer. Proc Natl Acad Sci USA 99: 13085-13089, 2002.

48. Staveley-O'Corrol K, Sotomayor E, Mongomery J, Borrello I, Hwang L, Fein S, Pardoll D and Levitsky H: Induction of antigen-specific T cell anergy: an early event in the course of tumor progression. Proc Natl Acad Sci USA 95: 1178-1183, 1998.

49. Finke J, Ferrone S, Frey A, Mufson A and Ochoa A: Where have all the T cells gone? Mechanisms of immune evasion by tumors. Immunol Today 20: 158-160, 1999.

50. Levy LS: Retrovirus-induced immunodeficiency and cancer. In: Retroviruses and Insights into Cancer. Dudley J (ed). Springer, New York, pp259-283, 2011.
51. Dunn GP, Bruce AT, Ikeda H, Old LJ and Schreiber RD: Cancer immunoediting: from immunosurveillance to tumor escape. Nat Immunol 3: 991-998, 2002.

52. Zitvogel L, Tesniere A and Kroemer G: Cancer despite immunosurveillance: immunoselection and immunosubversion. Nat Rev Immunol 6: 715-727, 2006.

53. Leslie AJ, Pfafferott KJ, Chetty P, Draenert R, Addo MM, Feeney M, Tang Y, Holmes EC, Allen T, Prado JG, Altfeld M, Brander C, Dixon C, Ramduth D, Jeena P, Thomas SA, St John A, Roach TA, Kupfer B, Luzzi G, Edwards A, Taylor G, Lyall H, Tudor-Williams G, Novelli V, Martinez-Picado J, Kiepiela P, Walker BD and Goulder PJ: HIV evolution: CTL escape mutation and reversion after transmission. Nat Med 10: 282-289, 2004.

54. Klenerman P, Wu Y and Phillips R: HIV: current opinion in escapology. Curr Opin Microbiol 5: 408-413, 2002.

55. Wang T, Niu G, Kortylewski M, Burdelya L, Shain K, Zhang S, Bhattacharya R, Gabrilovich D, Heller R, Coppola D, Dalton W, Jove R, Pardoll D and Yu H: Regulation of the innate and adaptive immune responses by Stat-3 signaling in tumor cells. Nat Med 10: 48-54, 2004.

56. Oosterhoff D, Lougheed S, van de Ven R, Lindenberg J, van Cruijsen H, Hiddingh L, Kroon J, van den Eertwegh AJ, Hangalapura B, Scheper RJ and de Gruijl TD: Tumor-mediated inhibition of human dendritic cell differentiation and function is consistently counteracted by combined p38 MAPK and STAT3 inhibition. Oncoimmunology 1: 649-658, 2012.

57. Lee CA, Phillips AN, Elford J, Janossy G, Griffiths P and Kernoff P: Progression of HIV disease in a haemophilic cohort followed for 11 years and the effect of treatment. BMJ 303: 1093-1096, 1991. Erratum in: BMJ 303: 1446, 1991.

58. Hammer SM, Katzenstein DA, Hughes MD, Gundacker H, Schooley RT, Haubrich RH, Henry WK, Lederman MM, Phair JP, Niu M, Hirsch MS and Merigan TC: A trial comparing nucleoside monotherapy with combination therapy in HIV-infected adults with CD4 cell counts from 200 to 500 per cubic millimeter. AIDS Clinical Trials Group Study 175 Study Team. N Engl J Med 335: 1081-1090, 1996.

59. Hammer SM, Squires KE, Hughes MD, Grimes JM, Demeter LM, Currier JS, Eron JJ Jr, Feinberg JE, Balfour HH Jr, Deyton LR, Chodakewitz JA and Fischl MA: A controlled trial of two nucleoside analogues plus indinavir in persons with human immunodeficiency virus infection and CD4 cell counts of 200 per cubic millimeter or less. AIDS Clinical Trials Group 320 Study Team. N Engl J Med 337: 725-733, 1997.

60. Leung D, Abbenante G and Fairlie DP: Protease inhibitors: current status and future prospects. J Med Chem 43: 305-341, 2000.

61. Sterne JA, Hernán MA, Ledergerber B, Tilling K, Weber R, Sendi P, Rickenbach M, Robins JM and Egger M; Swiss HIV Cohort Study: Long-term effectiveness of potent antiretroviral therapy in preventing AIDS and death: a prospective cohort study. Lancet 366: 378-384, 2005.

62. Saif MW, Katirtzoglou NA and Syrigos KN: Capecitabine: an overview of the side effects and their management. Anticancer Drugs 19: 447-464, 2008.

63. Hatziveis K, Tourlakis D, Hountis P, Kyriazanos I, Sougleri M, Ginopoulos P and Camoutsis C: Effects on the immune system and toxicity of carboplatin/paclitaxel combination chemotherapy in patients with stage III-IV ovarian and non-small cell lung cancer and its role in survival and toxicity. J BUON 17: 143-148, 2012.

64. Li T, Kung HJ, Mack PC and Gandara DR: Genotyping and genomic profiling of non-small-cell lung cancer: implications for current and future therapies. J Clin Oncol 31: 1039-1049, 2013.

65. Cohen MH, Gootenberg J, Keegan P and Pazdur R: FDA drug approval summary: bevacizumab (Avastin) plus Carboplatin and Paclitaxel as first-line treatment of advanced/metastatic recurrent nonsquamous non-small cell lung cancer. Oncologist $12: 713-718$, 2007.

66. Shaw AT, Solomon B and Kenudson MM: Crizotinib and testing for ALK. J Natl Compr Canc Netw 9: 1335-1341, 2011.

67. Takahashi S: Vascular endothelial growth factor (VEGF), VEGF receptors and their inhibitors for antiangiogenic tumor therapy. Biol Pharm Bull 34: 1785-1788, 2011.

68. Doi Y, Yashiro M, Yamada N, Amano R, Noda S and Hirakawa K: VEGF-A/VEGFR-2 signaling plays an important role for the motility of pancreas cancer cells. Ann Surg Oncol 19: 2733-2743, 2012. 
69. Olsson AK, Dimberg A, Kreuger J and Claesson-Welsh L: VEGF receptor signalling - in control of vascular function. Nat Rev Mol Cell Biol 7: 359-371, 2006.

70. Abrams TJ, Murray LJ, Pesenti E, Holway VW, Colombo T, Lee LB, Cherrington JM and Pryer NK: Preclinical evaluation of the tyrosine kinase inhibitor SU11248 as a single agent and in combination with 'standard of care' therapeutic agents for the treatment of breast cancer. Mol Cancer Ther 2: 1011-1021, 2003.

71. Ferrara N, Hillan KJ, Gerber HP and Novotny W: Discovery and development of bevacizumab, an anti-VEGF antibody for treating cancer. Nat Rev Drug Discov 3: 391-400, 2004.

72. Burger JA, Stewart DJ, Wald O and Peled A: Potential of CXCR4 antagonists for the treatment of metastatic lung cancer. Expert Rev Anticancer Ther 11: 621-630, 2011.

73. Zhao BC, Wang ZJ, Mao WZ, Ma HC, Han JG, Zhao B and $\mathrm{Xu}$ HM: CXCR4/SDF-1 axis is involved in lymph node metastasis of gastric carcinoma. World J Gastroenterol 17: 2389-23896, 2011.

74. Hou KL, Hao MG, Bo JJ and Wang JH: CXCR7 in tumorigenesis and progression. Chin J Cancer 29: 456-459, 2010.

75. Burger M, Glodek A, Hartmann T, Schmitt-Gräff A, Silberstein LE, Fujii N, Kipps TJ and Burger JA: Functional expression of CXCR4 (CD184) on small-cell lung cancer cells mediates migration, integrin activation, and adhesion to stromal cells. Oncogene 22: 8093-80101, 2003.

76. Soriano SF, Serrano A, Hernanz-Falcón P, Martín de Ana A, Monterrubio M, Martinez C, Rodríguez-Frade JM and Mellado M: Chemokines integrate JAK/STAT and G-protein pathways during chemotaxis and calcium flux responses. Eur $\mathbf{J}$ Immunol 33: 1328-1333, 2003

77. Kijima T, Maulik G, Ma PC, Tibaldi EV, Turner RE, Rollins B, Sattler M, Johnson BE and Salgia R: Regulation of cellular proliferation, cytoskeletal function, and signal transduction through CXCR4 and c-Kit in small cell lung cancer cells. Cancer Res 62: 6304-6311, 2002.

78. D'Alterio C, Barbieri A, Portella L, Palma G, Polimeno M, Riccio A, Ieranò C, Franco R, Scognamiglio G, Bryce J, Luciano A, Rea D, Arra C and Scala S: Inhibition of stromal CXCR4 impairs development of lung metastases. Cancer Immunol Immunother 61: 1713-1720, 2012.

79. Burns JM, Summers BC, Wang Y, Melikian A, Berahovich R, Miao Z, Penfold ME, Sunshine MJ, Littman DR, Kuo CJ, Wei K, McMaster BE, Wright K, Howard MC and Schall TJ: A novel chemokine receptor for SDF-1 and I-TAC involved in cell survival, cell adhesion, and tumor development. J Exp Med 203: 2201-2213, 2006.

80. Sharma M, Afrin F, Satija N, Tripathi RP and Gangenahalli GU: Stromal-derived factor-1/CXCR4 signaling: indispensable role in homing and engraftment of hematopoietic stem cells in bone marrow. Stem Cells Dev 20: 933-946, 2011.

81. D'Alterio C, Portella L, Ottaiano A, Rizzo M, Carteni G, Pignata S, Facchini G, Perdona S, Di Lorenzo G, Autorino R, Franco R, La Mura A, Nappi O, Castello G and Scala S: High CXCR4 expression correlates with sunitinib poor response in metastatic renal cancer. Curr Cancer Drug Targets 12: 693-702, 2012.
82. Zhao HB, Tang CL, Hou YL, Xue LR, Li MQ, Du MR and Li DJ: CXCL12/CXCR4 axis triggers the activation of EGF receptor and ERK signaling pathway in CsA-induced proliferation of human trophoblast cells. PLoS One 7: e38375, 2012.

83. Keating GM: Plerixafor: a review of its use in stem-cell mobilization in patients with lymphoma or multiple myeloma. Drugs 71: 1623-1647, 2011.

84. Attolico I, Pavone V, Ostuni A, Rossini B, Musso M, Crescimanno A, Martino M, Iacopino P, Milone G, Tedeschi P, Coluzzi S, Nuccorini R, Pascale S, Di Nardo E and Olivieri A: Plerixafor added to chemotherapy plus G-CSF is safe and allows adequate PBSC collection in predicted poor mobilizer patients with multiple myeloma or lymphoma. Biol Blood Marrow Transplant 18: 241-249, 2012.

85. Li JK, Yu L, Shen Y, Zhou LS, Wang YC and Zhang JH Inhibition of CXCR4 activity with AMD3100 decreases invasion of human colorectal cancer cells in vitro. World J Gastroenterol 14: 2308-2313, 2008

86. Garnier D, Magnus N, D'Asti E, Hashemi M, Meehan B, Milsom C and Rak J: Genetic pathways linking hemostasis and cancer. Thromb Res 129 (Suppl 1): S22-S29, 2012.

87. Nakanishi M, Sato T, Li Y, Nelson AJ, Farid M, Michalski J, Kanaji N, Wang X, Basma H, Patil A, Goraya J, Liu X, Togo S, L Toews M, Holz O, Muller KC, Magnussen H and Rennard SI: Prostaglandin E2 stimulates the production of vascular endothelial growth factor through the E-prostanoid-2 receptor in cultured human lung fibroblasts. Am J Respir Cell Mol Biol 46: 217-223, 2012.

88. Luo H, Chen Z, Jin H, Zhuang M, Wang T, Su C, Lei Y, Zou J and Zhong B: Cyclooxygenase-2 up-regulates vascular endothelial growth factor via a protein kinase $\mathrm{C}$ pathway in non-small cell lung cancer. J Exp Clin Cancer Res 30: 6, 2011.

89. Obermajer N, Muthuswamy R, Odunsi K, Edwards RP and Kalinski P: PGE(2)-induced CXCL12 production and CXCR4 expression controls the accumulation of human MDSCs in ovarian cancer environment. Cancer Res 71: 7463-7470, 2011.

90. Shimada K, Anai S, Marco DA, Fujimoto K and Konishi N: Cyclooxygenase 2-dependent and independent activation of Akt through casein kinase $2 \alpha$ contributes to human bladder cancer cell survival. BMC Urol 11: 8, 2011.

91. Pozzi A, Yan X, Macias-Perez I, Wei S, Hata AN, Breyer RM, Morrow JD and Capdevila JH: Colon carcinoma cell growth is associated with prostaglandin E2/EP4 receptor-evoked ERK activation. J Biol Chem 279: 29797-29804, 2004.

92. Schönthal AH: Exploiting cyclooxygenase-(in)dependent properties of COX-2 inhibitors for malignant glioma therapy. Anticancer Agents Med Chem 10: 450-461, 2010. 